\title{
Desempenho agronômico e qualidade físico-química de híbridos de tomateiro em cultivo rasteiro
}

\author{
Kélin Schwarz; Juliano Tadeu V de Resende; Ana Paula Preczenhak; Juliana T de Paula; Marcos V \\ Faria; Diego M Dias \\ UNICENTRO, Campus CEDETEG, Depto. Agronomia, C. Postal 3010, 85040-080 Guarapuava-PR; kelinschwarz@hotmail.com; \\ jvresende@uol.com.br; ana_paula772@hotmail.com; jutauffer@hotmail.com; mfaria@unicentro.br; diegomunhozdias@hotmail.com
}

\begin{abstract}
RESUMO
A avaliação de cultivares nas mesmas condições edafoclimáticas permite comparar genótipos quanto ao seu potencial de produtividade e qualidade de frutos, buscando os melhores para cada região. $\mathrm{O}$ trabalho objetivou avaliar o desempenho produtivo e a qualidade de frutos de híbridos de tomateiro cultivados de forma rasteira, visando a produção para processamento e mesa. $\mathrm{O}$ experimento foi conduzido em campo no município de Pinhão-PR, em dois anos agrícolas (2009/2010 e 2010/2011). O delineamento experimental consistiu em blocos casualizados com quatro repetições. Utilizou-se 10 híbridos de tomateiro (Supera, Granadero, AP-529, AP-533, Kátia, Laura, Fascínio, Tinto, Red Spring e Vênus). Avaliaram-se a produtividade total e comercial, massa média de frutos, frutos danificados, presença de pedúnculo e, características de qualidade (massa seca, firmeza, espessura de mesocarpo, sólidos solúveis, acidez titulável, relação sólidos solúveis/acidez titulável, $\mathrm{pH}$, licopeno, ácido ascórbico e açúcares redutores). Houve destaque para o híbrido Granadero que apresentou maior produtividade total (112,5 t ha-1 em 2009/2010 e $78,5 \mathrm{t} \mathrm{ha}^{-1}$ em 2010/2011) e comercial (88,7 t ha- em 2009/2010 e 69,0 t ha $^{-1}$ em 2010/2011) nos dois anos de experimento, bem como maior massa seca, maior teor de sólidos solúveis e maior espessura do mesocarpo. Tinto e Vênus também se destacaram na produtividade total e comercial e o híbrido com maior massa média foi Vênus $(99,9$ g). Na relação sólidos solúveis/acidez titulável, destacaram-se os híbridos Granadero, Vênus, Supera, Tinto e Fascínio, com valores acima de 10 em ambos os anos. Laura, Red Spring e Vênus apresentaram bons valores para ácido ascórbico e licopeno. Em geral, o híbrido com melhor desempenho para as características avaliadas e para ambos os segmentos foi Granadero, porém este híbrido demonstrou baixa estabilidade genotípica. Sendo assim, Vênus e Tinto, apesar das produtividades menores, poderiam ser recomendados, pois apresentaram boa qualidade e estabilidade para a região.
\end{abstract}

Palavras-chave: Solanum lycopersicum, produtividade, características físico-químicas.

\begin{abstract}
Agronomic performance and physico-chemical quality in tomato hybrids grown without guiding
\end{abstract}

The evaluation of cultivars within the same soil and climatic conditions allows comparison of genotypes for its yield and quality potential, seeking to establish the most adapted for each region. This study aimed to evaluate the yield and fruit quality of tomato hybrids grown without guiding, for fresh consumption and processing. The field experiment was carried out in Pinhão, Paraná state, Brazil, in two years (2009/2010 and 2010/2011). The experimental design was a randomized complete block with four replications. Ten tomato hybrids were used (Supera, Granadero, AP-529, AP-533, Kátia, Laura, Fascínio, Tinto, Red Spring and Vênus). We evaluated total and marketable yield, average fruit weight, fruit damage, presence of peduncle; and characteristics of quality: dry mass, fruit firmness, mesocarp thickness, soluble solids, titratable acidity, soluble solids/ titratable acidity ratio, $\mathrm{pH}$, ascorbic acid, lycopene and reducing sugars. Granadero was the hybrid with the highest total yield $(112.5 \mathrm{t}$ $\mathrm{ha}^{-1}$ in 2009/2010 and $78.5 \mathrm{t} \mathrm{ha}^{-1}$ in 2010/2011) and marketable yield (88.7 $\mathrm{t} \mathrm{ha}^{-1}$ in 2009/2010 and $69.0 \mathrm{t} \mathrm{ha}^{-1}$ in 2010/2011) in two years of experiment, as well as the highest dry matter and soluble solids and the highest mesocarp thickness. Tinto and Venus also stood out in total and marketable yield and the hybrid which had the highest average fruit weight was Venus (99.9 g). For the soluble solids/ titratable acidity ratio, Granadero, Venus, Supera, Tinto and Fascínio showed ratios above 10 in both years. Laura, Red Spring and Venus showed good values for ascorbic acid and lycopene. Overall, the best performing hybrid for traits and for both segments was Granadero, but this hybrid showed low genotypic stability. So Venus and Tinto, despite lower yields, could be recommended because they presented good quality and stability to the region.

Keywords: Solanum lycopersicum, yield, physico-chemical characteristics.

(Recebido para publicação em 30 de maio de 2012; aceito em 10 de julho de 2013) (Received on May 30, 2012; accepted on July 10, 2013)

$\mathrm{O}$ tomateiro (Solanum lycopersicum) é uma hortaliça que faz parte, diariamente, da alimentação de grande parte da população brasileira. Dentre as hortaliças é uma das mais importantes, não apenas em produção, mas também em valor socioeconômico. Em 2008 a produção brasileira de tomates, envolvendo ambos os segmentos, processamento e consumo in natura, alcançou 3,86 milhões de toneladas, em uma área de 61 mil hectares, com produtividade média em torno de $63 \mathrm{t} /$ ha, gerando um valor bruto da produção agrícola estimado em 2,4 bilhões de reais (IBGE, 2010).

A demanda por tomate tem sido reforçada pela busca de alimentos mais saudáveis, tendo em vista ser reservatório de diversas moléculas antioxidantes ou compostos bioativos, como ácido ascórbico, vitamina E, carotenoides e compostos fenólicos (George et al., 2004), assim o tomate é considerado um alimento funcional, favorecendo o crescimento da venda do produto fresco e industrializado. Há evidências de que 
sua ingestão regular tem correlação negativa com risco de doenças cardiovasculares e diferentes formas de câncer (Kris-Etherton et al., 2002).

Nos últimos anos, a produção de tomate passou por grandes transformações tecnológicas, destacando-se a utilização de híbridos de elevada produtividade e de "longa vida". Entretanto, a qualidade gustativa dos híbridos "longa vida" tem recebido críticas, pois os mesmos genes que conferem a característica desejável causam efeitos indesejáveis no sabor, aroma, textura e teor de licopeno (Boiteux et al., 2008). Ao mesmo tempo, o consumidor que valorizava mais o tamanho do fruto do que o sabor e o preço, tem procurado frutos menores e com melhor qualidade (Alvarenga, 2004). Assim, o tomate destinado ao processamento, cultivado de forma rasteira, vem ganhando espaço também no mercado de consumo in natura.

A sustentabilidade econômica das indústrias de processamento de tomate depende da qualidade da matéria-prima que determina, em grande parte, a qualidade do produto final. Já para os consumidores, a qualidade do tomate se refere àqueles atributos que o indivíduo consciente ou inconscientemente estima que o produto deva possuir. Há diferentes atributos desejáveis em tomate, dependendo da finalidade, tais como teor de sólidos solúveis ( ${ }^{\circ}$ Brix), sabor, acidez, cor, teor de licopeno, espessura do pericarpo e facilidade de remoção da pele dos frutos (Ferreira et al., 2004; Melo \& Vilela, 2005).

A avaliação de cultivares dentro das mesmas condições edafoclimáticas permite comparar genótipos quanto ao seu potencial produtivo, qualidade de frutos e resistência a doenças e pragas. É importante também para conhecer os mais adequados para cada região, pois cada material tem suas características genéticas que determinam sua maior ou menor sensibilidade às condições ambientais e a outros fatores de produção (Peixoto et al., 1999). Estudos com este propósito têm sido desenvolvidos no Brasil. Na região do Vale do São Francisco, 18 cultivares de tomateiro para processamento industrial foram cultivadas, obtendo-se produtividades comerciais que variaram de 70,8 a 96,6 t $\mathrm{ha}^{-1}$, teor de sólidos solúveis de 6,1 a 4,3 ${ }^{\circ}$ Brix e massa média de fruto de 110,9 a 75,4 g (Resende \& Costa, 2000). Já em ensaio de competição de híbridos realizado em Goiás, a produtividade variou de 65,1 a 124,3 $\mathrm{t} \mathrm{ha}^{-1}$ e o teor de sólidos solúveis de 5,9 a 3,9 ${ }^{\circ}$ Brix (Aragão et al., 2004).

Na região centro-sul do Paraná o tomateiro de cultivo rasteiro está em crescente expansão, gerando novos empregos e fontes de renda, tornando-se uma atividade de grande importância. Desde 2003 até a safra 2012, a área cultivada de tomate nesta região do $\mathrm{Pa}$ raná aumentou de 13 hectares para 195 hectares e a produção aumentou de 640 t para 7.983 t (SEAB, 2012). Entretanto, os híbridos de tomateiro mais plantados e recomendados no Brasil não foram desenvolvidos para essa região. Nesse contexto, surge a necessidade de pesquisas que busquem avaliar cultivares de tomateiro de hábito rasteiro, mais adaptadas e com características de interesse comercial que agreguem valor, além de cultivares que apresentem dupla aptidão (processamento e consumo in natura), atendendo às demandas e aumentando a versatilidade de comércio.

O presente trabalho teve por objetivo avaliar o desempenho de híbridos de tomateiro cultivados de forma rasteira visando identificar e recomendar os mais produtivos e com melhor qualidade de frutos para o processamento industrial e consumo in natura, nas condições da região centro-sul do Paraná.

\section{MATERIAL E MÉTODOS}

Foram conduzidos dois experimentos, nos anos 2009/2010 (experimento I) e 2010/2011 (experimento II), no município de Pinhão, na região centro-sul do Paraná (2541'12”'S, 51³8’45”O, 1.041 $\mathrm{m}$ de altitude). O solo é classificado como Latossolo Bruno e o clima subtropical úmido mesotérmico $\mathrm{Cfb}$, com verões frescos, invernos com ocorrência de geadas severas e frequentes, não apresentando estação seca (classificação de Köppen). A temperatura média anual é $18^{\circ} \mathrm{C}$.

Utilizou-se, em cada experimento, 10 híbridos de tomate (Supera, Grana- dero, AP-529, AP-533, Kátia, Laura, Fascínio, Tinto, Red Spring e Vênus) que foram cultivados de forma rasteira. Todos os híbridos são de crescimento determinado com exceção do híbrido Granadero. Os ensaios foram realizados em campo utilizando o delineamento experimental de blocos casualizados, com quatro repetições. Cada parcela foi composta por 20 plantas, divididas em duas linhas com 10 plantas cada. $\mathrm{O}$ espaçamento foi de $1,50 \mathrm{~m}$ entre linhas e $0,30 \mathrm{~m}$ entre plantas, totalizando $4,5 \mathrm{~m}^{2}$ por parcela, sendo que todas as plantas foram consideradas úteis.

As mudas foram produzidas em bandejas de 128 células preenchidas com substrato comercial, no Setor de Olericultura da UNICENTRO em casa de vegetação climatizada, com plástico de 150 micras, umidade relativa entre 70 e $80 \%$, temperatura média de 18 a $26^{\circ} \mathrm{C}$, irrigadas por microaspersão. $\mathrm{O}$ transplante das mudas no experimento I foi realizado em 17 de dezembro 2009, enquanto que no experimento II foi realizado em 31 de dezembro de 2010.

Para os dois anos de avaliação a adubação foi realizada nas linhas de plantio com uso de adubadora adaptada, adotando-se a análise do solo como base para recomendação para a cultura do tomateiro. Realizaram-se pulverizações de fungicidas e inseticidas (Mancozebe 300 g p.c. $100 \mathrm{~L}^{-1}$ água, Iprodiona 150 g p.c. $100 \mathrm{~L}^{-1}$ água, Tiofanato-metílico 70 g p.c. $100 \mathrm{~L}^{-1}$ água, Metomil $100 \mathrm{~mL}$ p.c. $100 \mathrm{~L}^{-1}$ água, Clorantraniliprole 15 $\mathrm{mL}$ p.c. $100 \mathrm{~L}^{-1}$ água, Imidacloprido 250 $\mathrm{mL}$ p.c. $100 \mathrm{~L}^{-1}$ água) intercalando-se os produtos e conforme a necessidade da cultura (geralmente foram realizadas duas aplicações por semana desde a emergência até o término da colheita). Para o controle das plantas espontâneas foram realizadas capinas manuais nas parcelas.

Para cada experimento foram realizadas três colheitas, iniciando a primeira aos 100 dias após o transplante das mudas no experimento I e aos 94 dias após o transplante das mudas no experimento II. As colheitas seguintes foram realizadas a cada 10 dias, para ambos os experimentos. Todos os tomates a partir do estádio de maturação breaker (frutos verde claro com o primeiro surgimento 
de mancha rosa, vermelha ou amarela cobrindo até $10 \%$ de sua superfície) foram colhidos.

Em ambos os experimentos determinou-se a produção total e comercial $(\mathrm{t}$ $\left.\mathrm{ha}^{-1}\right)$, a massa média de frutos $\left(\mathrm{g}_{\text {fruto }}{ }^{-1}\right)$, a porcentagem de perdas e de frutos com pedúnculo. Foram considerados comerciais os frutos com diâmetro transversal maior que $30 \mathrm{~mm}$, e que não apresentavam defeitos como podridão por fungos, decomposição por compressão ou ação de agentes microbiológicos, presença de larvas, rachaduras e podridão apical, sendo que os tomates com estes defeitos foram descartados e considerados como perdas (Brasil, 1988, 1995). O valor do diâmetro mínimo para aproveitamento do tomate foi uma adaptação dos valores encontrados nas portarias que definem padrões de qualidade para o tomate de mesa e de indústria (Portaria n. 278 de 1988 e Portaria n. 553 de 1995, ambas do MAPA), visto que a pesquisa objetivava produção para consumo in natura e para o processamento. Após estas avaliações foram separados 20 frutos por parcela, os quais apresentavam estádio de maturação caracterizado pela coloração vermelha, tamanho e coloração uniforme, ausência de pedúnculo, livres de danos mecânicos ou fisiológicos, pragas e doenças. Depois de separados, os frutos foram levados ao Laboratório de Fisiologia Vegetal, onde foram avaliadas a firmeza e espessura do mesocarpo. A firmeza dos frutos foi determinada com auxílio de penetrômetro digital (Soil Control PDF-200) com ponteira de 8 $\mathrm{mm}$ de diâmetro. As medidas foram realizadas após a remoção da casca, tomando-se duas leituras por fruto, em lados opostos de sua região equatorial, sendo os resultados expressos em Newton (N). Para avaliação da espessura de mesocarpo os frutos foram cortados longitudinalmente e, com auxílio de um paquímetro digital, procedeu-se a tomada de três medidas em cada fruto, sendo uma no ápice, uma no meio e uma na base. A partir das três medidas obteve-se a média.

Avaliadas a firmeza e espessura, imediatamente foram retiradas as sementes dos frutos para serem congelados a $-18^{\circ} \mathrm{C}$, devidamente separados conforme o tratamento. Para as análises subsequentes, os tomates foram descongelados e a polpa homogeneizada em triturador doméstico, sendo determinadas a massa seca por diferença de massa, em amostras submetidas à secagem em estufa de circulação forçada de ar, à temperatura de $70^{\circ} \mathrm{C}$, até peso constante; teor de sólidos solúveis (SS), determinado em refratômetro de bancada (Optech modelo RMT) após filtragem em algodão da polpa triturada, sendo os valores expressos em ${ }^{\circ}$ Brix; teor de açúcares redutores (AR), determinado pelo método Lane-Eynon (IAL, 2005) e os resultados expressos em \% de açúcares redutores; a acidez titulável (AT), por meio de titulação com $\mathrm{NaOH} 0,1 \mathrm{~mol} \mathrm{~L}^{-1}$ até pH 8,2 (IAL, 2005), expressando-se os resultados em mg ácido cítrico 100 $\mathrm{g}^{-1}$ de polpa; relação SS/AT; $\mathrm{pH}$ por leitura em potenciômetro (MS Tecnopon modelo mPA-210) diretamente na polpa de tomate triturada; teor de ácido ascórbico (AA), determinado por método titulométrico padrão da Association of Official Analitical Chemists (AOAC) modificado por Benassi \& Antunes (1988) e expresso em mg ácido ascórbico $100 \mathrm{~g}^{-1}$ polpa; teor de licopeno (LI), obtido por análise espectrofotométrica de acordo com o método descrito por Rodriguez-Amaya (2001) e os resultados expressos em $\mu \mathrm{g}$ licopeno $\mathrm{g}^{-1}$ polpa.

Os dados de cada experimento foram submetidos à análise de variância e, posteriormente, após a constatação da homogeneidade das variâncias residuais, realizou-se a análise conjunta. Para a comparação das médias entre os híbridos empregou-se o teste de Scott-Knott a 5\% e, para a comparação entre os anos, aplicou-se o teste F.

\section{RESULTADOS E DISCUSSÃO}

Os resultados da análise de variância conjunta revelaram diferenças significativas $(\mathrm{p}<0,05)$ para os híbridos em todas as características. A interação híbridos vs. anos foi significativa para todas as características, exceto para a massa média de fruto e teor de massa seca.

A produção total de frutos dos híbridos variou de 37,2 a $112,5 \mathrm{t} \mathrm{ha}^{-1}$ no primeiro ano e de 37,8 a 78,5 $\mathrm{t} \mathrm{ha}^{-1}$ no segundo ano (Tabela 1). Em ambos os anos, o híbrido Granadero destacou-se com a maior produção, diferindo estatisticamente dos demais, seguido dos híbridos Tinto, Vênus, AP-533 e Kátia no primeiro ano e dos híbridos Tinto e Vênus no segundo ano. A produção total do híbrido Granadero diminuiu do primeiro para o segundo ano, enquanto a produção total do híbrido Fascínio aumentou do primeiro para o segundo ano. Os demais híbridos não apresentaram diferença do primeiro para o segundo ano (Tabela 1). Em ambos os anos o híbrido Granadero apresentou produtividades superiores à média nacional do ano de 2008 (63 tha $\left.\mathrm{th}^{-1}\right)$ e à média do estado do Paraná de 2010 (64,4 t ha $\left.{ }^{-1}\right)$ (IBGE, 2010; SEAB, 2012).

A produtividade comercial variou de 28,8 a $88,7 \mathrm{tha}^{-1}$ no primeiro ano e de 33,4 a 69,0 t ha $^{-1}$ no segundo ano (Tabela 1). O híbrido Granadero se destacou, com maior produtividade comercial nos dois anos, seguido pelos híbridos Vênus, Tinto, AP-533 e Kátia no primeiro ano e Tinto e Vênus no segundo ano. Embora tenha apresentado a maior produção total e comercial em ambos os anos, o híbrido Granadero apresentou diminuição da produção (tanto comercial como total) do primeiro para o segundo ano, fato que pode estar relacionado à menor estabilidade genética deste material em relação aos outros, o que pode ser um ponto negativo tendo em vista que este material sofre grande influência no seu potencial produtivo em decorrência de alterações nas condições edafoclimáticas.

Os demais híbridos, com exceção do Fascínio cuja produção comercial aumentou do primeiro para o segundo ano, não apresentaram diferenças na produção comercial entre os anos. Para ambos os segmentos, processamento e consumo in natura, altas produtividades são interessantes, já que representam maior rentabilidade para os produtores. Além disso, quando se avaliam cultivares em um determinado ambiente, altas produtividades indicam melhor adaptação àquela região.

Em outras regiões do país, estudos com híbridos de tomateiro cultivados de forma rasteira mostraram resultados um pouco diferentes e que variaram de 70,9 a 96,7 $\mathrm{t} \mathrm{ha}^{-1}$ em Pernambuco (Resende 
Tabela 1. Produtividade total (PT), produtividade comercial (PC), frutos danificados (FD) e presença de pedúnculo (PP) em híbridos de tomateiro cultivados de forma rasteira em dois anos na região centro-sul do Paraná (total yield (PT), marketable yield (PC), fruit damage (FD) and presence of peduncle (PP) in tomato hybrids crop without guiding in two years in South Central Paraná). Guarapuava, UNICENTRO, 2011.

\begin{tabular}{|c|c|c|c|c|c|c|c|c|}
\hline \multirow{2}{*}{ Híbrido } & \multicolumn{2}{|c|}{ PT (t/ha) } & \multicolumn{2}{|c|}{ PC (t/ha) } & \multicolumn{2}{|c|}{ FD (\%) } & \multicolumn{2}{|c|}{ PP (\%) } \\
\hline & Ano I & Ano II & Ano I & Ano II & Ano I & Ano II & Ano I & Ano II \\
\hline Granadero & $112,5 \mathrm{Aa}$ & $78,5 \mathrm{Ba}$ & $88,7 \mathrm{Aa}$ & $69,0 \mathrm{Ba}$ & $21,2 \mathrm{Ab}$ & $12,2 \mathrm{Bb}$ & $3,4 \mathrm{Bb}$ & $27,8 \mathrm{Ab}$ \\
\hline Tinto & $68,8 \mathrm{Ab}$ & $68,2 \mathrm{Ab}$ & $48,3 \mathrm{Bb}$ & $61,1 \mathrm{Ab}$ & $30,5 \mathrm{Aa}$ & $10,4 \mathrm{Bb}$ & $20,1 \mathrm{Ba}$ & $50,9 \mathrm{Aa}$ \\
\hline Vênus & $67,3 \mathrm{Ab}$ & $66,1 \mathrm{Ab}$ & $50,3 \mathrm{Ab}$ & $54,0 \mathrm{Ab}$ & $26,3 \mathrm{Aa}$ & $18,6 \mathrm{Ba}$ & $3,1 \mathrm{Ab}$ & $3,0 \mathrm{Ac}$ \\
\hline AP-533 & $56,3 \mathrm{Ab}$ & $53,3 \mathrm{Ac}$ & $47,4 \mathrm{Ab}$ & $47,8 \mathrm{Ac}$ & $16,2 \mathrm{Ab}$ & $10,6 \mathrm{Ab}$ & $11,1 \mathrm{Bb}$ & $23,0 \mathrm{Ab}$ \\
\hline Kátia & $54,7 \mathrm{Ab}$ & $50,9 \mathrm{Ac}$ & $40,0 \mathrm{Ab}$ & $45,6 \mathrm{Ac}$ & $27,0 \mathrm{Aa}$ & $10,6 \mathrm{Bb}$ & $0,7 \mathrm{Ab}$ & $1,8 \mathrm{Ac}$ \\
\hline Red Spring & $44,5 \mathrm{Ac}$ & $42,1 \mathrm{Ad}$ & $34,3 \mathrm{Ac}$ & $37,6 \mathrm{Ad}$ & $23,0 \mathrm{Ab}$ & $10,5 \mathrm{Bb}$ & $5,0 \mathrm{Ab}$ & $5,4 \mathrm{Ac}$ \\
\hline AP-529 & $42,4 \mathrm{Ac}$ & 44,9 Ad & $33,2 \mathrm{Ac}$ & $40,4 \mathrm{Ad}$ & $21,8 \mathrm{Ab}$ & $10,4 \mathrm{Bb}$ & 26,3 Aa & $38,0 \mathrm{Aa}$ \\
\hline Fascínio & $39,6 \mathrm{Bc}$ & $55,1 \mathrm{Ac}$ & $28,8 \mathrm{Bc}$ & 49,4 Ac & $26,2 \mathrm{Aa}$ & $10,5 \mathrm{Bb}$ & $26,7 \mathrm{Ba}$ & $39,8 \mathrm{Aa}$ \\
\hline Supera & $37,9 \mathrm{Ac}$ & $42,1 \mathrm{Ad}$ & $31,0 \mathrm{Ac}$ & $36,2 \mathrm{Ad}$ & $18,1 \mathrm{Ab}$ & $14,0 \mathrm{Ab}$ & $6,6 \mathrm{Ab}$ & $2,8 \mathrm{Ac}$ \\
\hline Laura & $37,2 \mathrm{Ac}$ & $37,8 \mathrm{Ad}$ & $30,4 \mathrm{Ac}$ & $33,4 \mathrm{Ad}$ & $18,5 \mathrm{Ab}$ & $11,9 \mathrm{Bb}$ & $2,1 \mathrm{Ab}$ & $9,1 \mathrm{Ac}$ \\
\hline CV (\%) & 19,1 & 12,9 & 22,3 & 13,8 & 23,7 & 25,0 & 53,0 & 51,2 \\
\hline
\end{tabular}

Médias seguidas pela mesma letra maiúscula na linha não diferem estatisticamente entre si pelo teste $\mathrm{F}$ a $5 \%$ e médias seguidas pela mesma letra minúscula na coluna não diferem estatisticamente entre si pelo teste de Scott-Knott a 5\% (means followed by the same capital letter in line do not differ significantly, according to $\mathrm{F}$ test $\mathrm{p}<0.05$ and means followed by the same tiny letter in the column do not differ significantly, according to Scott-Knott's test $\mathrm{p}<0.05$ ).

Tabela 2. Massa média de frutos (MM) e teor de massa seca (MS) de híbridos de tomateiro cultivados de forma rasteira na região centro-sul do Paraná, considerando a média de dois anos de avaliação (average fruit weight (MM) and dry matter content (MS) in tomato hybrid crop without guiding in South Central Paraná, considering the average of two years of experiments). Guarapuava, UNICENTRO, 2011.

\begin{tabular}{lcc}
\hline Híbrido & MM (g) & MS (\%) \\
\hline Granadero & $75,2 \mathrm{c}$ & $5,2 \mathrm{a}$ \\
Tinto & $86,0 \mathrm{~b}$ & $4,5 \mathrm{~b}$ \\
Vênus & $99,9 \mathrm{a}$ & $4,7 \mathrm{~b}$ \\
AP-533 & $61,0 \mathrm{~d}$ & $4,0 \mathrm{c}$ \\
Katia & $59,8 \mathrm{~d}$ & $4,6 \mathrm{~b}$ \\
Red Spring & $51,3 \mathrm{e}$ & $4,0 \mathrm{c}$ \\
AP-529 & $53,7 \mathrm{e}$ & $4,5 \mathrm{~b}$ \\
Fascinio & $89,9 \mathrm{~b}$ & $4,0 \mathrm{c}$ \\
Supera & $69,2 \mathrm{~d}$ & $4,1 \mathrm{c}$ \\
Laura & $50,3 \mathrm{e}$ & $4,6 \mathrm{~b}$ \\
\hline CV (\%) & 14,9 & 10,8
\end{tabular}

Médias seguidas pela mesma letra na coluna não diferem estatisticamente entre si pelo teste de Scott-Knott a 5\% de probabilidade. (means followed by the same letter in the column do not differ significantly, according to Scott-Knott's test $\mathrm{p}<0.05$ ).

\& Costa, 2000), 65,2 a 124,3 $\mathrm{t} \mathrm{ha}^{-1} \mathrm{em}$ Goiás (Aragão et al., 2004); 80,6 a 101,8 t ha-1 em São Paulo (Seleguini et al., 2007). Nota-se que as médias de produtividade destas pesquisas foram superiores à média de produtividade de grande parte dos híbridos do presente estudo. Presumivelmente, isso se deve à interação genótipo x ambiente, ou seja, é provável que os híbridos cultivados nestas regiões sejam mais adaptados a elas, tendo em vista a condição climática específica. A elevada pluviosidade comumente observada na região de condução do presente trabalho pode ter contribuído para aumento na incidência de doenças bem como na lixiviação mais acelerada de nutrientes, implicando, portanto, em menores valores de produtividade quando comparado às regiões supracitadas. Outro fator que deve ser considerado para justificar as diferenças de produtividade observadas consiste na divergência entre as épocas de cultivo de cada região, tendo em vista que o plantio em Goiás e em São Paulo ocorre de fevereiro a junho, em Pernambuco de março a junho e na região da pesquisa em questão de outubro a janeiro.

No que concerne à massa média de frutos, o híbrido Vênus apresentou o maior valor $\left(99,9 \mathrm{~g}_{\text {fruto }^{-1}}\right)$, diferindo significativamente dos demais, seguido pelos híbridos Fascínio $\left(89,9 \mathrm{~g}_{\text {fruto }}{ }^{-1}\right)$ e Tinto (86,0 $\mathrm{g}_{\text {fruto }}{ }^{-1}$ ) (Tabela 2). Estes resultados estão dentro do esperado para tomates de cultivo rasteiro, pois Seleguini et al. (2007) encontraram massa média de frutos que variou entre 53,2 g e 96,6 g e Peixoto et al. (1999) observaram massa média entre 30 e 90 $\mathrm{g}$ fruto $^{-1}$. Para o consumo in natura, os consumidores que valorizavam mais o tamanho dos frutos, agora buscam por qualidade e sabor que geralmente são melhores em frutos menores, em função da menor absorção de água e maior concentração de ácidos e açúcares (Fernandes et al., 2002). 
Tabela 3. Firmeza de fruto (FIR), espessura de mesocarpo (ESP), teor de sólidos solúveis (SS), acidez titulável (AT), relação sólidos solúveis/ acidez titulável (SS/AT), pH, açúcares redutores (AR), licopeno (LI) e ácido ascórbico (AA) em híbridos de tomateiro cultivado de forma rasteira em dois anos na região centro-sul do Paraná (fruit firmness (FIR), mesocarp thickness (ESP), soluble solids (SS), titratable acidity (AT) and soluble solids/titratable acidity ratio (SS/AT) in tomato hybrids crop without guiding in two years in South Central of Paraná). Guarapuava, UNICENTRO, 2011.

\begin{tabular}{|c|c|c|c|c|c|c|c|c|c|c|c|c|}
\hline \multirow{2}{*}{ Híbrido } & \multicolumn{3}{|c|}{ FIR (N) } & \multicolumn{2}{|c|}{$\operatorname{ESP}(\mathbf{m m})$} & \multicolumn{2}{|c|}{ SS ( ${ }^{\circ}$ Brix) } & \multicolumn{3}{|c|}{$\mathrm{AT}\left(\mathrm{mg} 100 \mathrm{~g}^{-1}\right)$} & \multicolumn{2}{|c|}{ SS/AT } \\
\hline & Ano I & \multicolumn{2}{|c|}{ Ano II } & Ano I & Ano II & Ano I & Ano II & \multicolumn{2}{|c|}{ Ano I } & Ano II & Ano I & Ano II \\
\hline Granadero & $10,0 \mathrm{Aa}$ & \multicolumn{2}{|c|}{$10,4 \mathrm{Aa}$} & $7,5 \mathrm{Aa}$ & $8,3 \mathrm{Aa}$ & $5,42 \mathrm{Aa}$ & $5,00 \mathrm{Ba}$ & \multicolumn{2}{|c|}{$430 \mathrm{Ab}$} & $380 \mathrm{Bb}$ & $12,6 \mathrm{Aa}$ & $13,2 \mathrm{Aa}$ \\
\hline Laura & $13,6 \mathrm{Aa}$ & \multicolumn{2}{|c|}{$7,2 \mathrm{Bc}$} & $5,2 \mathrm{Bb}$ & $6,1 \mathrm{Ac}$ & $4,67 \mathrm{Ab}$ & 3,96 Bd & \multicolumn{2}{|c|}{$470 \mathrm{Aa}$} & $420 \mathrm{Ba}$ & $10,0 \mathrm{Ac}$ & $9,5 \mathrm{Ad}$ \\
\hline Katia & 11,1 Aa & \multicolumn{2}{|c|}{ 7,1 Bc } & $5,1 \mathrm{Bb}$ & $6,3 \mathrm{Ac}$ & $4,67 \mathrm{Ab}$ & $4,06 \mathrm{Bc}$ & \multicolumn{2}{|c|}{$370 \mathrm{Be}$} & $420 \mathrm{Aa}$ & $12,7 \mathrm{Aa}$ & $9,7 \mathrm{Bd}$ \\
\hline Red Spring & $11,8 \mathrm{Aa}$ & \multicolumn{2}{|c|}{ 7,6 Bc } & $5,3 \mathrm{Bb}$ & $6,9 \mathrm{Ab}$ & $4,50 \mathrm{Ab}$ & $4,26 \mathrm{Bb}$ & \multicolumn{2}{|c|}{$390 \mathrm{Bd}$} & $430 \mathrm{Aa}$ & $11,6 \mathrm{Ab}$ & $9,8 \mathrm{Bd}$ \\
\hline Vênus & $10,7 \mathrm{Aa}$ & \multicolumn{2}{|c|}{$5,3 \mathrm{Bc}$} & $5,4 \mathrm{Ab}$ & $5,6 \mathrm{Ac}$ & 4,42 Ac & $4,26 \mathrm{Ab}$ & \multicolumn{2}{|c|}{$410 \mathrm{Ac}$} & $380 \mathrm{Bb}$ & $10,7 \mathrm{Bb}$ & $11,4 \mathrm{Ac}$ \\
\hline Supera & 13,9 Aa & \multicolumn{2}{|c|}{$7,5 \mathrm{Bc}$} & $5,2 \mathrm{Ab}$ & $5,5 \mathrm{Ac}$ & $4,33 \mathrm{Ac}$ & 3,63 Be & \multicolumn{2}{|c|}{$340 \mathrm{Af}$} & $310 \mathrm{Bc}$ & $12,7 \mathrm{Aa}$ & $11,7 \mathrm{Bc}$ \\
\hline AP 529 & $11,9 \mathrm{Aa}$ & \multicolumn{2}{|c|}{$8,0 \mathrm{Bb}$} & $5,0 \mathrm{Ab}$ & $5,7 \mathrm{Ac}$ & $4,33 \mathrm{Ac}$ & 3,93 Bd & \multicolumn{2}{|c|}{$390 \mathrm{Ad}$} & $410 \mathrm{Aa}$ & $11,1 \mathrm{Ab}$ & $9,6 \mathrm{Bd}$ \\
\hline Tinto & 9,5 Aa & 6,3 & & $4,5 \mathrm{Bb}$ & $5,7 \mathrm{Ac}$ & $4,33 \mathrm{Ac}$ & $4,06 \mathrm{Bc}$ & 35 & Af & $330 \mathrm{Bc}$ & $12,2 \mathrm{Aa}$ & $12,4 \mathrm{Ab}$ \\
\hline AP 533 & 11,9 Aa & 8,3 & & $5,5 \mathrm{Ab}$ & $5,1 \mathrm{Ac}$ & $4,25 \mathrm{Ac}$ & $4,06 \mathrm{Bc}$ & & & $420 \mathrm{Aa}$ & $12,3 \mathrm{Aa}$ & $9,8 \mathrm{Bd}$ \\
\hline Fascínio & $11,4 \mathrm{Aa}$ & 8,3 & & $5,4 \mathrm{Bb}$ & $7,1 \mathrm{Ab}$ & $4,25 \mathrm{Ac}$ & 3,93 Bd & & $\mathrm{Ad}$ & $370 \mathrm{Ab}$ & $11,1 \mathrm{Ab}$ & $10,5 \mathrm{Ad}$ \\
\hline CV (\%) & 16,6 & 17 & & 10,6 & 8,5 & 1,4 & 1,5 & & & 3,1 & 4,0 & 3,8 \\
\hline & & p & & & AR & $(\%)$ & & LI ( & $g^{-1}$ & & $\mathrm{AA}(\mathrm{mg}$ & $\left.100 \mathrm{~g}^{-1}\right)$ \\
\hline & Anc & & & & Ano I & Ano II & & & & o II & Ano I & Ano II \\
\hline Granadero & 4,45 & & & & $1,88 \mathrm{Bb}$ & $2,25 \mathrm{Aa}$ & & $\mathrm{Bd}$ & & $\mathrm{Ae}$ & $10,6 \mathrm{Ba}$ & $14,4 \mathrm{Ab}$ \\
\hline Laura & 4,37 & & & & $1,77 \mathrm{Bc}$ & $2,03 \mathrm{Aa}$ & & $\mathrm{Aa}$ & & $\mathrm{Bd}$ & $10,4 \mathrm{Aa}$ & $9,8 \mathrm{Bd}$ \\
\hline Katia & 4,58 & $\mathrm{Bg}$ & & Af & $1,76 \mathrm{Ac}$ & $1,66 \mathrm{Ab}$ & & $\mathrm{Bg}$ & & $\mathrm{Ad}$ & $5,4 \mathrm{Bf}$ & $6,4 \mathrm{Ag}$ \\
\hline Red Spring & 4,43 & $\mathrm{Bb}$ & & & $1,72 \mathrm{Ac}$ & $1,74 \mathrm{Ab}$ & & $\mathrm{Bb}$ & & $A b$ & $10,1 \mathrm{Aa}$ & $9,5 \mathrm{Bd}$ \\
\hline Vênus & 4,44 & & & Ad & $1,84 \mathrm{Ab}$ & $1,84 \mathrm{Ab}$ & & $\mathrm{Bh}$ & & $5 \mathrm{Ac}$ & $9,3 \mathrm{Bb}$ & $16,2 \mathrm{Aa}$ \\
\hline Supera & 4,47 & $\mathrm{Bd}$ & & & $1,56 \mathrm{Ae}$ & $1,56 \mathrm{Ab}$ & & $\mathrm{Bc}$ & & $\mathrm{Ac}$ & $7,5 \mathrm{Ad}$ & $7,0 \mathrm{Bf}$ \\
\hline AP 529 & 4,53 & $\mathrm{Be}$ & & & $1,51 \mathrm{Ae}$ & $1,65 \mathrm{Ab}$ & & $\mathrm{Be}$ & & $\mathrm{Aa}$ & 7,5 Ad & $5,3 \mathrm{Bi}$ \\
\hline Tinto & 4,53 & $\mathrm{Be}$ & & & 1,61 Ad & $1,50 \mathrm{Ab}$ & & $\mathrm{Bf}$ & & $7 \mathrm{Af}$ & $8,6 \mathrm{Ac}$ & 7,4 Be \\
\hline AP 533 & 4,55 & $\mathrm{Bf}$ & & & $1,65 \mathrm{Ad}$ & $1,57 \mathrm{Ab}$ & & $\mathrm{Bd}$ & & $5 \mathrm{Ac}$ & $5,5 \mathrm{Af}$ & $4,1 \mathrm{Bh}$ \\
\hline Fascínio & 4,47 & $\mathrm{Bd}$ & & & $2,15 \mathrm{Aa}$ & $1,60 \mathrm{Bb}$ & & $\mathrm{Bg}$ & & $\mathrm{Ab}$ & $6,7 \mathrm{Be}$ & $10,3 \mathrm{Ac}$ \\
\hline CV (\%) & 0,2 & & & & 3,3 & 8,0 & & & & 8 & 4,8 & 2,0 \\
\hline
\end{tabular}

Médias seguidas pela mesma letra maiúscula na linha não diferem estatisticamente entre si pelo teste $\mathrm{F}$ a $5 \%$ e médias seguidas pela mesma letra minúscula na coluna não diferem estatisticamente entre si pelo teste de Scott-Knott a 5\% [means followed by the same capital letter in line do not differ significantly, according to $\mathrm{F}$ test $(\mathrm{p}<0.05)$ and means followed by the same tiny letter in the column do not differ significantly, according to Scott-Knott's test $(\mathrm{p}<0.05)]$.

Com relação aos frutos danificados (Tabela 1), no primeiro ano as menores perdas foram observadas nos híbridos AP-533, Supera, Laura, Granadero, AP-529 e Red Spring, sendo que, no geral, as perdas oscilaram entre 16,2 a $30,5 \%$, enquanto que no segundo ano, as perdas foram menores, variando de 10,4 a $18,6 \%$, sendo que o híbrido Vênus diferiu estatisticamente dos demais por apresentar a maior porcentagem de perdas $(18,6 \%)$. Considerando que o híbrido Vênus obteve a maior massa média de fruto, mesmo que as perdas deste híbrido fossem menores, a produtividade ainda não seria a mais elevada, pois a produtividade total não chega aos valores do híbrido mais produtivo (Granadero).

Do primeiro para o segundo ano, as perdas diminuíram significativamente para todos os híbridos, com exceção dos híbridos AP-533 e Supera, cujos valores de perdas não diferiram entre os anos (Tabela 1). As maiores perdas no primeiro ano são atribuídas, provavelmente, ao período de chuvas consecutivas que antecedeu a primeira colheita, acarretando alta umidade e, consequentemente, mais problemas fitossanitários. E, embora a precipitação tenha sido menor no período das colheitas no segundo ano, esta foi mais elevada no período de floração do segundo ano de experimento em comparação com o primeiro (Figuras 1 e $2 b$ ), o que pode explicar porque as menores perdas não refletiram em aumento da produção (Silva \& Giordano, 2000).

Outra característica de interesse são os frutos que apresentam fenótipo jointless, ou seja, ausência da junta de abscisão no pedúnculo do fruto (Silva \& Giordano, 2000). No presente trabalho, verificou-se que a porcentagem de frutos com pedúnculo aderido no primeiro e segundo ano de experimento foram de 0,7 até $26,7 \%$ e 1,8 a $50,9 \%$, respectivamente (Tabela 1 ), sendo que para os 
dois anos de cultivo, os híbridos com menor retenção de pedúnculo foram Kátia, Laura, Vênus, Granadero, Red Spring, Supera e AP-533, demonstrando, portanto, maior potencial genético destes materiais para a característica avaliada. Em relação aos dois anos de experimento, a presença de pedúnculo foi estatisticamente superior no segundo ano para os híbridos Granadero (de 3,4 para $27,8 \%$ ), Tinto (de 20,1 para 50,9\%), AP-533 (de 11,1 para 23,0\%) e Fascínio (de 26,7 para 39,8\%). Para os demais não houve diferença entre os anos (Tabela 1). Esta diferença entre os anos pode estar relacionada ao estádio de maturação em que os frutos se encontravam no momento da colheita, pois no segundo ano pode ter ocorrido a concentração de frutos mais 'verdes' em algumas plantas, já que a colheita foi mais precoce. Isso pode ter contribuído para a maior retenção de pedúnculo nos frutos, visto que neste estádio, o equilíbrio auxina/etileno ainda não está promovendo a abscisão dos frutos, os quais estão mais fortemente ligados ao pedúnculo.

No primeiro ano, os valores encontrados para a firmeza de fruto estiveram entre 9,46 e 13,90 N e não houve diferenças significativas entre os híbridos (Tabela 3). Já no segundo ano, houve diferenças significativas, com destaque para o híbrido Granadero, revelando a maior firmeza $(10,43 \mathrm{~N})$. Os valores da firmeza dos frutos dos demais híbridos variaram de 5,32 a 8,33 N (Tabela 3). De acordo com estes valores, os frutos do presente estudo se enquadram na classificação "muito macio" (5 N), "macio" $(10 \mathrm{~N})$ e "moderadamente macio" (10 a 15 N) (Cantwell, 2004). Neste caso, os frutos 'moderadamente macios', ou seja, com maior firmeza, são aqueles com melhor capacidade de armazenamento e transporte, pois a firmeza afeta a suscetibilidade dos tomates a danos físicos e, consequentemente, sua aptidão para comercialização (Villas Boas et al., 2000).

Em relação aos anos de experimento, somente o híbrido Granadero manteve a firmeza semelhante em ambos os anos; para os demais híbridos a firmeza diminuiu significativamente do primeiro para o segundo ano (Tabela 3 ). No segundo ano, as colheitas foram mais precoces do que no primeiro ano, com isso a concentração de frutos verdes foi maior e, consequentemente, se esperava maiores firmezas. No entanto, é possível que a diminuição na firmeza dos frutos colhidos possa estar relacionada com as maiores variações de temperatura observadas durante parte da colheita no segundo ano de experimento em comparação com o primeiro (Figuras 1 e 2a). Diferenças extremas de temperatura não estão diretamente relacionadas com a firmeza do fruto, porém, há evidências de que a temperatura pode influenciar na degradação da parede celular, resultando em amolecimento do fruto (Jewell, 2004). Além disso, as temperaturas foram um pouco mais altas durante as colheitas do segundo ano (Figuras 1 e 2a), o que também pode ter influenciado na degradação da parede celular e amolecimento do fruto. Ressalta-se que as temperaturas mais elevadas no segundo ano, estão acima da média dos últimos 10 anos (Figura 2a).

Quanto à espessura do mesocarpo (Tabela 3), o híbrido Granadero foi estatisticamente superior aos demais nos dois anos de avaliação, apresentando espessura de 7,5 mm e $8,3 \mathrm{~mm}$, no primeiro e segundo ano, respectivamente. Isso, possivelmente, está relacionado com as características genéticas próprias do híbrido e a interação com o ambiente em que foi cultivado. Em relação aos dois anos de experimento, os híbridos Laura, Kátia, Red Spring, Tinto e Fascínio apresentaram aumento significativo em relação à espessura do mesocarpo do primeiro para o segundo ano, o que pode estar relacionado à maior precipitação durante o ciclo da cultura no segundo ano, deixando os frutos mais túrgidos e, por consequência, com maior espessura. Os demais híbridos não apresentaram diferenças significativas entre os anos (Tabela 3).

Corroborando com a espessura de mesocarpo, o teor de massa seca foi superior para o híbrido Granadero, podendo-se inferir que a espessura do mesocarpo está relacionada ao rendimento. A variação dos teores de massa seca entre os híbridos foi de 4 a 5,2\% (Tabela 2), sendo estes valores semelhantes aos encontrados em outros estudos que caracterizaram frutos de tomate (Fernandes et al., 2002; Fagundes et al., 2005; Monteiro et al., 2008), bem como próximos aos valores para tomate encontrados na tabela brasileira de composição de alimentos (TACO, Unicamp, 2011). Para consumo in natura, frutos com maior teor de umidade são mais apreciados pelo consumidor, pois são mais suculentos, contudo para a indústria são necessários frutos com maior teor de massa seca, pois proporcionam maior rendimento (Fagundes et al., 2005). Sendo assim, aqueles híbridos com maior teor de massa seca (como Granadero, Vênus, Tinto, AP529) poderão ser melhor aproveitados pela indústria, porém não os descarta para o consumo in natura, já que, os valores de massa seca encontrados no presente estudo condizem com aqueles geralmente encontrados para tomates em geral, aos quais os consumidores já estão habituados.

Com relação ao teor de sólidos solúveis o híbrido Granadero atingiu os maiores valores nos dois anos de experimento, diferindo significativamente dos demais (Tabela 3). Ainda, no primeiro ano, destacaram-se os híbridos Laura (4,67 ${ }^{\circ}$ Brix), Kátia $\left(4,67^{\circ}\right.$ Brix) e Red Spring (4,50 Brix), que assim como o Granadero, apresentaram teor de sólidos solúveis superior ao valor médio do tomate destinado para o processamento industrial, que é de $4,5^{\circ}$ Brix (Silva \& Giordano, 2000). As variações no teor de sólidos solúveis entre os frutos de diferentes genótipos são esperadas, pois há diversos fatores que influenciam, dentre os quais a capacidade do fruto de importar assimilados fotossintéticos (Young et al., 1993).

Houve redução no teor de sólidos solúveis do primeiro para o segundo ano para todos os híbridos, exceto para o híbrido Vênus, o qual manteve o teor (Tabela 3). Os baixos teores de sólidos solúveis no segundo ano podem estar relacionados com a maior pluviosidade durante o ciclo da cultura em relação ao primeiro experimento $(700,4 \mathrm{~mm}$ no segundo ano e $612,3 \mathrm{~mm}$ no primeiro ano) (Figuras 1 e 2b), já que o excesso de chuvas pode reduzir o teor de sólidos solúveis (Silva \& Giordano, 2000). Este fato também foi observado 


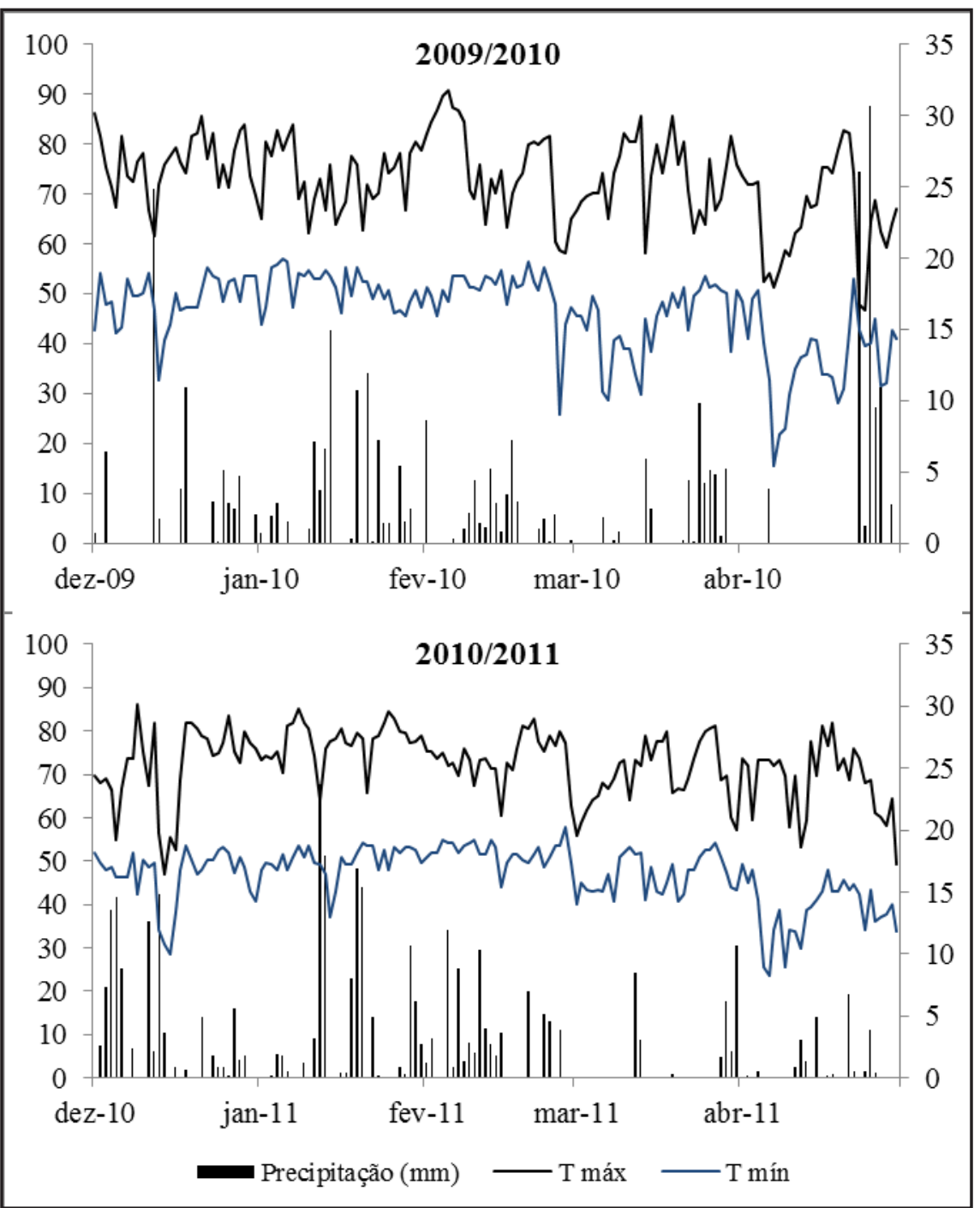

Figura 1. Dados climáticos das safras 2009/2010 e 2010/2011 da região de Guarapuava-PR (climatic data of 2009/2010 and 2010/2011 crops in the region of Guarapuava, Paraná state). Fonte: Estação Meteorológica do Campus CEDETEG e IAPAR. Guarapuava, UNICENTRO, 2011.

por Cintra et al. (2000), que testaram híbridos de tomate para processamento e não observaram valores de sólidos solúveis superiores a $4,0^{\circ}$ Brix, devido a alta pluviosidade. Para o processamento industrial, quanto maior for o teor de sólidos solúveis no fruto, maior será o rendimento e menor o gasto de energia no processo de concentração da polpa (Silva \& Giordano, 2000). Já para o consumo do tomate in natura, o teor de sólidos solúveis de $3,0^{\circ}$ Brix é considerado ideal para frutos de alta qualidade, desde que haja equilíbrio com a acidez titulável (Kader et al., 1978). Desta forma, considerando o teor de sólidos solúveis, os híbridos colhidos em ambos os experimentos poderiam ser comercializados para consumo in natura, pois nenhum deles apresentou teor abaixo de $3,0^{\circ}$ Brix.

$\mathrm{O}$ teor de açúcares redutores diferiu entre os dois anos de experimento apenas para os híbridos Granadero e Laura, cujo teor de açúcares redutores aumentou do primeiro para o segundo ano e, para o híbrido Fascínio, cujo teor diminuiu do primeiro para o segundo ano (Tabela 3). No primeiro ano, os teores variaram de 1,51 a $2,15 \%$ e, no segundo ano, de 1,50 a 2,25\% (Tabela 3 ). As diferenças observadas no teor de açúcares redutores de um ano para o outro para alguns híbridos, podem ser devido ao grau de amadurecimento em que se encontravam, pois apesar de serem selecionados em relação ao tamanho e coloração, pequenas mudanças podem ocorrer. Os teores mais elevados foram observados no híbrido Fascínio, no primeiro ano, e nos híbridos Granadero e Laura no segundo ano. O maior conteúdo de açúcares redutores está correlacionado com a maior doçura do fruto. Além disso, juntamente com a acidez titulável, os açúcares redutores influenciam a intensidade do aroma, flavor e sabor (Auerswald et al., 1999), importantes para a escolha do consumidor.

A acidez titulável dos frutos diminuiu significativamente do primeiro para o segundo ano de avaliação para os híbridos Granadero, Laura, Vênus, Supera e Tinto e aumentou para os híbridos Kátia, Red Spring e AP-533. Já a acidez titulável dos frutos dos híbridos AP-529 e Fascínio não diferiu entre os anos (Tabela 3). No primeiro ano, o híbrido Laura (470 mg ácido cítrico 100 $\left.\mathrm{g}^{-1}\right)$ foi estatisticamente superior aos demais e, no segundo ano os híbridos que se destacaram foram Red Spring (430 mg ácido cítrico $\left.100 \mathrm{~g}^{-1}\right)$, Laura, Kátia e AP-533 (420 mg ácido cítrico $100 \mathrm{~g}^{-1}$ ) e AP-529 (410 mg ácido cítrico $100 \mathrm{~g} \mathrm{~g}^{-1}$ ) que também demonstraram valores superiores quando comparados aos demais (Tabela 3). Os valores encontrados no estudo em questão estão próximos aos encontrados por Carvalho et al. (2005), em experimento com tomates destinados ao consumo in natura. A acidez titulável influencia o sabor e está relacionada ao aproveitamento pela indústria, pois tomates com valores abaixo de 350 $\mathrm{mg} 100 \mathrm{~g}^{-1}$ de fruto fresco requerem aumento no tempo e temperatura de processamento para evitar a proliferação de microrganismos nos produtos processados (Silva \& Giordano, 2000).

Valores elevados para a relação SS/ AT indicam sabor suave devido à excelente combinação de açúcar e ácido, enquanto valores baixos se correlacionam com sabor ácido (Ferreira et al., 2004). No primeiro ano de avaliação, os frutos dos híbridos apresentaram boa relação SS/AT (Tabela 2), já que a maior parte atingiu valores acima de 10 , o que é recomendável segundo Kader et al. (1978) que afirma que frutos de alta qualidade apresentam relação SS/AT 
a)
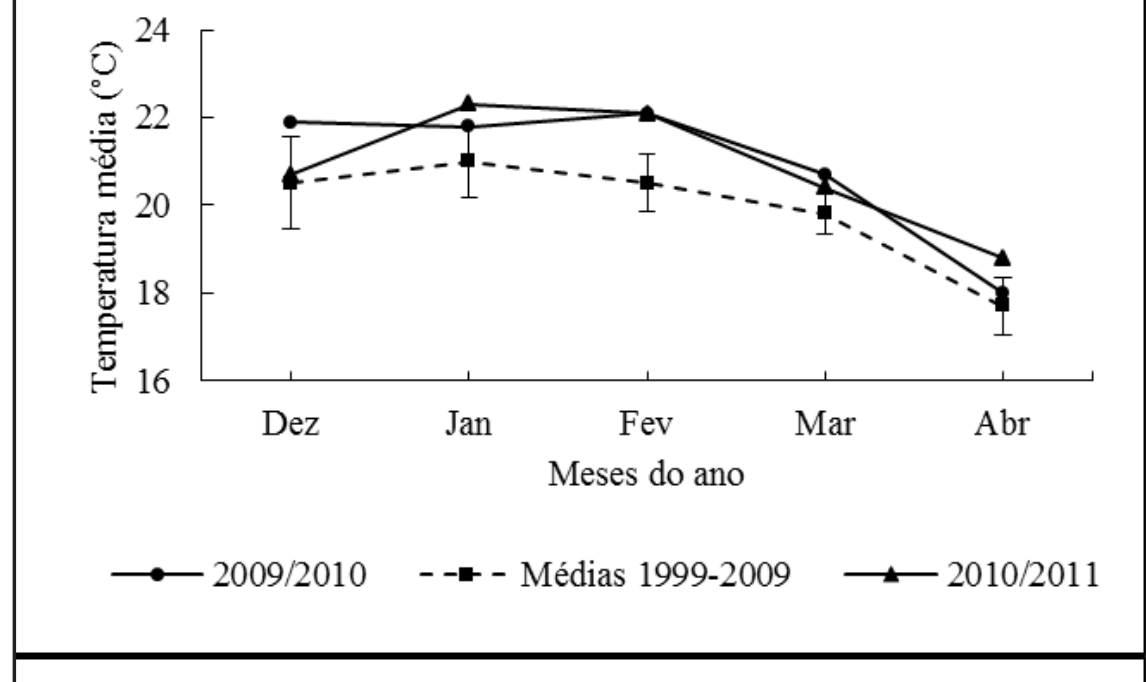

b)

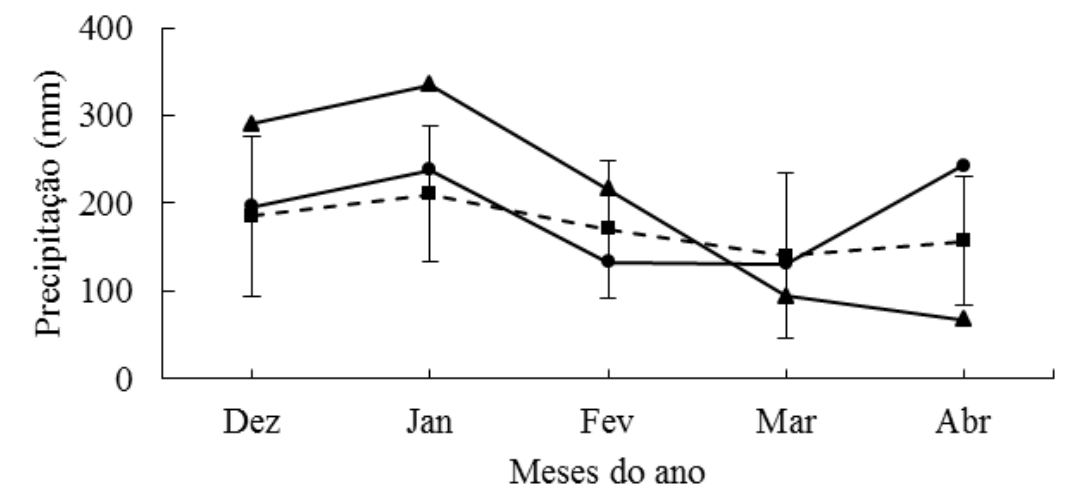

—2009/2010 ---- Médias 1999-2009

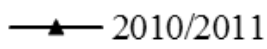

Figura 2. Comparação entre os dados climáticos da média de 1999-2009 e das safras 2009/2010 e 2010/2011 da região de Guarapuava-PR: a) Temperatura; b) Precipitação (comparison between the climatic data of the average 1999-2009 and 2009/2010 and 2010/2011 crops in the region of Guarapuava, Paraná state a) Temperature b) Precipitation). Fonte: Estação Meteorológica do Campus CEDETEG e IAPAR. Guarapuava, UNICENTRO, 2011.

maior que 10 . No segundo ano de avaliação metade dos híbridos apresentou relação SS/AT abaixo de 10 (Tabela 3), entretanto, houve destaque, novamente para o híbrido Granadero, com a maior relação, 13,2, diferindo dos demais. Além disso, o híbrido Granadero não apresentou diferenças significativas para a relação SS/AT quando comparados os dois anos de experimento, assim como não houve diferenças em relação aos anos de avaliação para os híbridos Laura, Kátia e Fascínio. Os demais híbridos apresentaram diminuição na relação SS/ AT do primeiro para o segundo ano de anos o híbrido Kátia apresentou o maior valor de $\mathrm{pH}$. Ainda, os valores de $\mathrm{pH}$ de todos os híbridos avaliados estão dentro ou próximo do intervalo considerado ideal para tomate, que é entre 3,7 e 4,5 (Silva \& Giordano, 2000), valores estes adequados para ambos os segmentos. $\mathrm{pH}$ inferior a 4,5 evita a proliferação de microrganismos e diminui o período de esterilização da matéria-prima (Monteiro et al., 2008) enquanto que, tomates com pH não tão ácido são preferidos pelo consumidor (Borguini \& Silva, 2007).

Quanto ao ácido ascórbico, no primeiro ano de avaliação, os híbridos Granadero, Laura e Red Spring, apresentaram maior teor com respectivamente 10,6; 10,4 e 10,1 mg ácido ascórbico 100 $\mathrm{g}^{-1}$ polpa (Tabela 3 ). No segundo ano, os teores de ácido ascórbico variaram de 4,1 a $16,2 \mathrm{mg} 100 \mathrm{~g}^{-1}$, destacando-se o híbrido Vênus, estatisticamente superior aos demais. Houve aumento significativo no teor de ácido ascórbico do primeiro para o segundo ano nos híbridos Granadero, Kátia, Vênus e Fascínio. Os demais híbridos apresentaram diminuição no teor de ácido ascórbico. Sampaio \& Fontes (1988), afirmam que o teor de ácido ascórbico no fruto do tomateiro pode variar de 7,2 a 45,6 mg $100 \mathrm{~g}^{-1}$ de polpa e, depende da época do ano, cultivar, intensidade luminosa, adubação e solo, sendo assim, a maior parte dos híbridos do experimento em questão apresentaram resultados dentro do esperado para esta característica. E, quando se considera o consumo de tomate in natura, o teor de ácido ascórbico é fator relevante, já que o processamento pode levar à degradação do mesmo.

Os teores de licopeno variaram conforme o híbrido e o ano do cultivo e foram semelhantes aos encontrados por Shirahige et al. (2010) e Georgé et al. (2011). No primeiro ano, o híbrido Laura se destacou dos demais $\left(72,1 \mu \mathrm{g} \mathrm{g}^{-1}\right)$, enquanto no segundo ano, o híbrido com maior teor foi AP-529 (47,9 $\left.\mu \mathrm{g} \mathrm{g}^{-1}\right)$. Com exceção dos híbridos Laura e Tinto, cujos teores de licopeno diminuíram do primeiro para o segundo ano, os demais híbridos apresentaram aumento nos teores de licopeno (Tabela 3). Isto ocorreu, possivelmente, porque as temperaturas durante o período de maturação dos frutos do segundo ano de experimento 
foram um pouco mais elevadas do que as do primeiro ano (Figura 1), ficando mais próximas da temperatura ótima para o desenvolvimento da coloração vermelha do tomate $\left(20\right.$ a $\left.24^{\circ} \mathrm{C}\right)$ (Alvarenga, 2004). A concentração do licopeno no tomate está relacionada com a melhor percepção visual dos produtos, existindo, uma forte demanda para aumentar os teores deste pigmento em frutos tanto para consumo in natura quanto para processamento industrial. Além disso, há o fator nutricional, pois o licopeno possui conhecidas propriedades antioxidantes (Kris-Etherton et al., 2002).

Deste modo, percebe-se que as características avaliadas foram influenciadas pela constituição genotípica dos híbridos, bem como pelas condições edafoclimáticas às quais foram submetidos. Em termos gerais, o híbrido com melhor desempenho para as características avaliadas e para ambos os segmentos foi o Granadero, embora tenha apresentado baixa estabilidade genotípica para a produtividade. Vênus e Tinto, apesar das menores produtividades, apresentaram desempenho razoável nas condições do centro-sul do Paraná e podem ser destinados tanto para consumo in natura como para o processamento, o que permite recomendá-los para o cultivo nesta região.

\section{AGRADECIMENTOS}

A Leandro Bren e Klaus Ferter, apoiadores da pesquisa. À Capes pela concessão de bolsa.

\section{REFERÊNCIAS}

ALVARENGA MAR. 2004. Tomate: produção em campo, casa-de-vegetação e em hidroponia. Lavras: UFLA. 400p.

ARAGÃO FAS; GIORDANO LB; MELO PCT; BOITEUX LS. 2004. Desempenho de híbridos experimentais de tomateiro para processamento industrial nas condições edafoclimáticas do cerrado brasileiro. Horticultura Brasileira 22: 529-533.

AUERSWALD H; SCHWARZ, D; KORNELSON C; KRUMBEIN A; BRÜCKNER B. 1999. Sensory analysis, sugar and acid content of tomato at different EC values of the nutrient solution. Scientia Horticulturae 82: 227-242.

BENASSI MT; ANTUNES AJ. 1988. A comparison of methaphosphoric and oxalic acids as extractant solutions for the determination of vitamin $\mathrm{C}$ in selected vegetables. Brazilian Archives of Biology and Technology 31: 507-513.

BOITEUX LS; MELO PCT; VILELA JV. 2008. Tomate para consumo in natura. In: ALBUQUERQUE ACS; SILVA AG (orgs). Agricultura tropical: quatro décadas de inovações tecnológicas, institucionais e políticas. Brasília: Embrapa Informação Tecnológica. p. 557-567.

BORGUINI RG; SILVA MV. 2007. O conteúdo nutricional de tomates obtidos por cultivo orgânico e convencional. Revista Higiene Alimentar 45: 41-46.

BRASIL. Ministério da Agricultura, Pecuária e Abastecimento. Portaria $n^{\circ} 553$ de 30 de agosto de 1995. Dispõe sobre a Norma de Identidade, Qualidade Acondicionamento e Embalagem do Tomate in natura, para fins de comercialização. Diário Oficial da República Federativa do Brasil, Brasília, 1995.

BRASIL. Ministério da Agricultura, Pecuária e Abastecimento. Portaria $n^{\circ} 278$ de 30 de novembro de 1988. Norma de identidade, qualidade, embalagem e apresentação do tomate para indústria. Diário Oficial da República Federativa do Brasil, Brasília, 1988.

CANTWELL M. 2004. Fresh-cut vegetables. USA: University of California, Davis. p. 78-85. Postharvest Horticulture Series n. 10.

CARVALHO LA; NETO JT; ARRUDA MC; JACOMINO AP; MELO PCT. 2005. Caracterização físico-química de híbridos de tomate de crescimento indeterminado em função do espaçamento e número de ramos por planta. Revista Brasileira de Agrociência 11: 295-298.

CINTRA AAD; GRILLI GVG; BRAZ LT; SANTOS GM; BRAZ BA. 2000. Caracterização de frutos de cultivares de tomateiro para processamento. Horticultura Brasileira 18: 723-725.

FAGUNDES AF; ONUKI NS; RAUPP DS; GARDINGO JR; BORSATO AV. 2005. Influência do grau de umidade na textura do tomate seco refrigerado ou envasado em óleo. Ciências Exatas e da Terra 1: 35-42.

FERNANDES AA; MARTINEZ HEP; FONTES PCR. 2002. Produtividade, qualidade dos frutos e estado nutricional do tomateiro tipo longa vida conduzido com um cacho, em cultivo hidropônico, em função das fontes de nutrientes. Horticultura Brasileira 20: 564-570.

FERREIRA SMR; FREITAS RJS; LAZZARI EN. 2004. Padrão de identidade e qualidade do tomate (Lycopersicon esculentum) de mesa. Ciência Rural 34: 329-335.

GEORGE B; KAUR C; KHURDIYA DS; KAPOOR HC. 2004. Antioxidants in tomato (Lycopersium esculentum) as a function of genotype. Food Chemistry 84: 45-51.

GEORGÉ S; TOURNIAIRE F; GAUTIER H; GOUPY P; ROCK E; CARIS-VEYRAT C. 2011. Changes in the contents of carotenoids, phenolic compounds and vitamin $\mathrm{C}$ during technical processing and lyophilisation of red and yellow tomatoes. Food Chemistry 124: 1603-1611.

IAL. INSTITUTO ADOLFO LUTZ. Brasil.
Ministério da Saúde. Agência Nacional de Vigilância Sanitária. 2005. Métodos físicoquímicos para análise de alimentos. Brasília: Ministério da Saúde.

INSTITUTO BRASILEIRO DE GEOGRAFIA E ESTATÍSTICA - IBGE. Sistema IBGE de recuperação automática, SIDRA. 2010, 20 de maio. Produção agrícola municipal 2008. Disponível em http://www.ibge.gov.br

KADER AA; MORRIS LL; STEVENS MA; ALBRIGHT-HOLTON M. 1978. Composition and flavor quality of fresh market tomato as influenced by some postharvest handling procedures. Journal of the American Society for Horticultural Science 103: 6-13.

KRIS-ETHERTON PM; HECKER KD; BONANOME A; COVAL SM; BINKOSKI AE; HILPERT KF; GRIEL AE; ETHERTON TD. 2002. Bioactive compounds in foods: their role in the prevention of cardiovascular disease and cancer. American Journal of Medicine 113: 71S-88S.

MELO PCT; VILELA NJ. 2005. Desafios e perspectivas para a cadeia brasileira do tomate para processamento industrial. Horticultura Brasileira 23: 154-157.

MONTEIRO CS; BALBI ME; MIGUEL OG; PENTEADO PTPS; HARACEMIV AMC. 2008. Qualidade nutricional e antioxidante do tomate "tipo italiano". Alimentos e Nutrição 19: 25-31.

PEIXOTO N; MENDONÇA JL; SILVA JBC; BARBEDO ASC. 1999. Rendimento de cultivares de tomate para processamento em Goiás. Horticultura Brasileira 17: 54-57.

RESENDE GM; COSTAND. 2000. Produtividade de tomate industrial no Vale do São Francisco. Horticultura Brasileira. 18: 126-129.

RODRIGUEZ-AMAYADA. Guide to Carotenoids Analysis in Food. 2001. Washington: International Life Sciences Institute Press. 64p.

SAMPAIO RA; FONTES PCR. 1988. Qualidade de frutos de tomateiro fertirrigado com potássio em solo coberto com polietileno preto. Horticultura Brasileira 16: 136-139.

SECRETARIA DA AGRICULTURA E DO ABASTECIMENTO DO PARANÁ - SEAB. 2012, 5 de novembro. Produção agrícola do Estado do Paraná. Disponível em http://www. seab.pr.gov.br/.

SELEGUINI A; SENO S; FARIA JÚNIOR MJA. 2007. Híbridos de tomateiro industrial cultivados em ambiente protegido e campo aberto. Cientifica 35: 80-87.

SHIRAHIGE FH; MELO AMT; PURQUERIO LFV; CARVALHO CRL; MELO PCT. 2010. Produtividade e qualidade de tomates Santa Cruz e Italiano em função do raleio de frutos. Horticultura Brasileira 28: 292-298.

SILVA JBC; GIORDANO LB. 2000. Tomate para processamento industrial. Brasília: EMBRAPA/Hortaliças. 168p.

VILAS BOAS EVB; CHITARRA AB; MALUF WR; CHITARRA MIF. 2000. Modificações texturais de tomates heterozigotos no loco Alcobaça. Pesquisa Agropecuária Brasileira 35: 447-1453.

YOUNG TE; JUVIK JA; SULLIVAN JG. 1993. Accumulation of the components of total solids in ripening fruits of tomato. Journal of the American Society for Horticultural Science 118: 286- 292. 